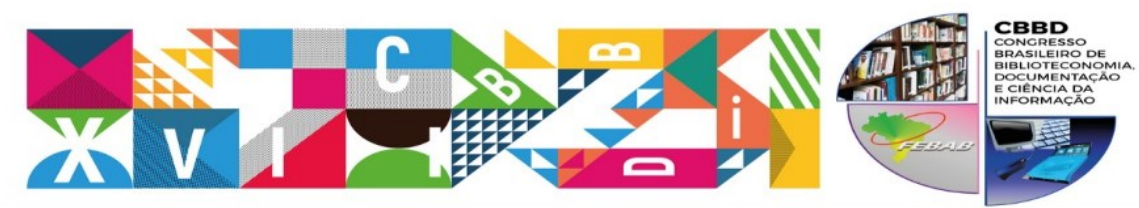

XXVII CONGRESSO BRASILEIRO DE BIBLIOTECONOMIA,

DOCUMENTAÇÃO E CIÊNCIA DA INFORMAÇÃO

TEMA CENTral: Objetivos para o Desenvolvimento Sustentável das Naçōes Unidas:
como as bibliotecas podem contribuir com a implementaçāo da Agenda 2030

Eixo 8 - Advocacy, Inovação e Empreendedorismo

AGENDA 2030:

\title{
uma proposta de advocacy junto às bibliotecas das universidades públicas de Florianópolis-SC
}

Sigrid K. Weiss Dutra

Bibliotecária da Universidade Federal de Santa Catarina.

E-mail: sigrid.k.weiss@gmail.com

\section{Marli Dias de Souza Pinto}

Professora Adjunta do Programa de Pós-graduação em Ciência da Informação e dos cursos de graduação do Departamento de Ciência da Informação da

Universidade Federal de Santa

Catarina.

E-mail: marli.dias@ufsc.br

\section{Genilson Geraldo}

Graduando em Biblioteconomia pela Universidade Federal de Santa Catarina.

E-mail:

genilsongeraldo.biblio@gmail.com

\section{RESUMO}

A Ciência da Informação sinaliza a necessidade de se pensar um novo paradigma social, e para este estudo, resgata-se uma aproximação com a Biblioteca universitária que sucintamente centra-se na organização e disponibilização do conhecimento numa perspectiva sistêmica. 0 estudo se caracteriza como exploratório, com abordagem qualitativa, e o caminho metodológico compreendeu o envio de questionário aos gestores de bibliotecas de Bibliotecas Universitárias Federais e uma pesquisa bibliográfica para verificar o estado da arte sobre o tema em questão. 0 propósito deste estudo é propor ações alinhadas ao Internacional Advocacy Program (IAP) da IFLA, visando sensibilizar e conscientizar, os bibliotecários a nível regional e local, utilizando o Advocacy, como instrumento na defesa da inserção das bibliotecas universitárias nas metas e Objetivos de Desenvolvimento Sustentável, previsto na Agenda 2030 da ONU, mediante o desenvolvimento de um programa junto às bibliotecas das universidades públicas, sediadas no município de Florianópolis-SC.

Palavra chaves:Bibliotecas universitárias. Advogacy. Agenda 2030 ONU. Objetivos de Desenvolvimento Sustentável (ODS).

AGENDA 2030:a proposal for advocacy towards the libraries of the public universities of Florianópolis-SC ABSTRACT

The Information Science signals the need to think about a new social paradigm, and for this study, an approach is redeemed with the University Library, which succinctly focuses on the organization and availability of knowledge from a systemic perspective. The study is characterized as exploratory, with a qualitative approach, and the methodological path included the sending of a 


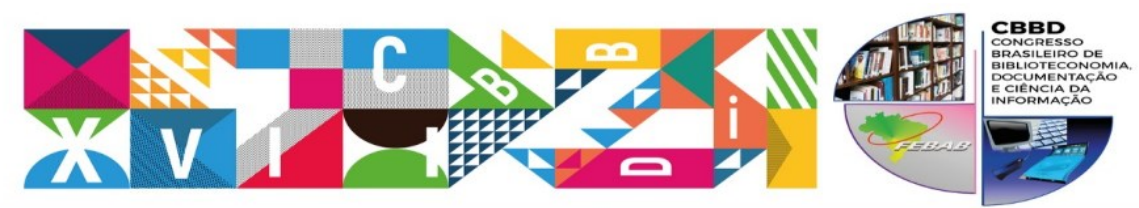

XXVII CONGRESSO BRASILEIRO DE BIBLIOTECONOMIA,

DOCUMENTAÇÃO E CIÊNCIA DA INFORMAÇÃO

TEMA CENTral: Objetivos para o Desenvolvimento Sustentável das Naçōes Unidas:
como as bibliotecas podem contribuir com a implementaçāo da Agenda 2030

questionnaire to the managers of libraries of Federal University Libraries and a bibliographical research to verify the state of the art on the subject in question. The purpose of this study is to propose actions aligned with the International Advocacy Program (IAP) of IFLA, aiming to raise awareness and awareness of librarians at regional and local level, using Advocacy as a tool to defend the insertion of university libraries in the goals and objectives of Development Program 2030, through the development of a program with the public universities' libraries, located in the city of Florianópolis$\mathrm{SC}$.

KeYwords:University libraries. Advocacy. Agenda 2030. SustainableDevelopmentObjectives (ODS)

\section{INTRODUÇÃO}

A Ciência da Informação sinaliza a necessidade de se pensar um novo paradigma social, e para este estudo, resgata-se uma aproximação com a Biblioteca.

Especialmente, nesta reflexão a biblioteca universitária é o foco do estudo, por que entendemos sua atuação, amplamente voltada para o ensino, a pesquisa e a extensão em que o emprego do desenvolvimento sustentável, possibilitará empreender ações baseadas nos direitos humanos, mediante a inserção de competências, educação e inclusão, numa visão sistêmica dos aspectos sociais, econômicos, culturais e ambientais, de sua comunidade usuária e de seu entorno.

As bibliotecas universitárias de instituições federais de ensino são espaços geradores e disseminadores do conhecimento, que podem incluir a sustentabilidade numa uma visão sistêmica favorecendo, a continuidade das ações humanas e organizacionais.

Contemporaneamente, sabe-se que muitos são os desafios para a gestão das bibliotecas universitárias, que vão desde o estabelecimento de estratégias para minimizar fatores frágeis de toda ordem, até capacidade de adaptação às turbulências que emergem com mudanças sociais, econômicas e tecnológicas, abrangendo mais amplamente os serviços e produtos, alinhados com as necessidades informacionais, em 


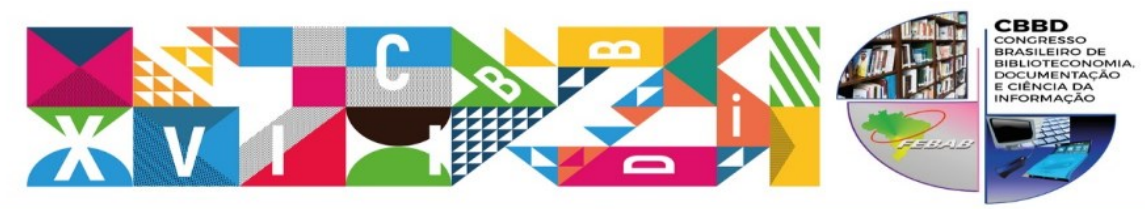

XXVII CONGRESSO BRASILEIRO DE BIBLIOTECONOMIA, DOCUMENTAÇÃO E CIÊNCIA DA INFORMAÇĀO

TEMA CENrRaA: Objetivos para o Desenvolvimento Sustentável das Naçōes Unidas:
como as bibliotecas podem contribuir com a implementaçâo da Agenda 2030

todos os contextos, e além de tudo isto pode ainda contribuir para o desenvolvimento sustentável.

Inicialmente para desenvolver o presente estudo elaborou-se um questionário com base nas 17 metas da Agenda de Desenvolvimento da Organização das Nações Unidas (ONU) para verificar como as bibliotecas universitárias podem promover a Agenda 2030? O respectivo instrumento de coleta de dados foi enviado para os diretores de bibliotecas universitárias das 63 (sessenta e três) instituições federais de ensino superior brasileira, procedeu a dois momentos de envios e no reenvio dos questionários foram incluídas as bibliotecas privadas e, neste processo apenas um questionário retornou respondido.

Os pesquisadores entenderam que esta não devolução de dados dos questionários, apresentou-se como uma possibilidade de estudo, e que era mais importante divulgar a Agenda do que questionar. Neste cenário, verificou-se como alternativa o estudo do Internacional Advocacy Program (IAP) que busca dar subsídios, capacitação, promover e apoiar o papel das bibliotecas no desempenho, no planejamento e implementação da Agenda 2030 da ONU. Deste modo, por tudo que foi descrito até aqui, a questão da investigação busca saber: Como alinhar-se ao Internacional Advocacy Program (IAP) da IFLA na sensibilização e conscientização a nível regional da inclusão das bibliotecas nos Planos Nacionais de Desenvolvimento em consonância com a Agenda 2030 da ONU?

O tema deste estudo foi tratado amplamente no Congresso Brasileiro de Biblioteconomia e Documentação (CBBD), um evento importante de responsabilidade da Federação Brasileira das Associações de Bibliotecários (FEBAB), realizado em outubro de 2017, que objetivou discutir o estado da arte da Biblioteconomia e da Ciência da Informação e integrar os profissionais das bibliotecas brasileiras de todas as tipologias: escolares, públicas, comunitárias, universitárias e especializadas (CBBD, 2017). Nessa edição do CBBD o tema central foi os “Objetivos para o Desenvolvimento Sustentável das Nações Unidas: como as bibliotecas podem contribuir com a implementação da Agenda $2030 "$

Tanto no cenário, seja organizacional ou informacional, tudo acontece em tempo real, para Weber (2011) a biblioteca como instituição informacional é organismo vivo 


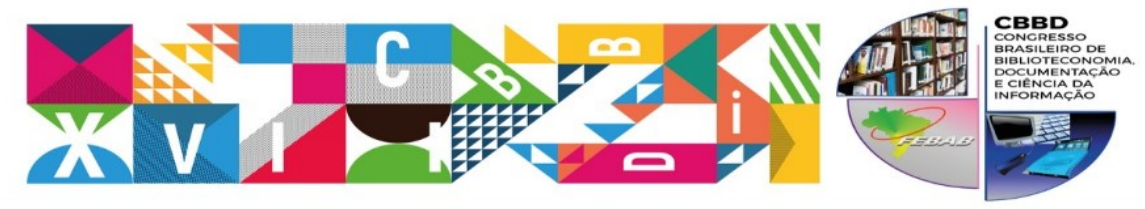

XXVII CONGRESSO BRASILEIRO DE BIBLIOTECONOMIA, DOCUMENTAÇÃO E CIÊNCIA DA INFORMAÇÃO

TEMA CENIRal: Objetivos para o Desenvolvimento Sustentável das Naçōes Unidas:
como as bibliotecas podem contribuir com a implementaçăo da Agenda 2030

dinâmico e crescente, é impelida a ser pensada em alicerces e nas diretrizes que norteiam a sustentabilidade.

O desenvolvimento sustentável presume uma maneira de agir no momento presente pensando no futuro da sociedade, para tanto a conscientização é ponto chave deste processo, foi a partir deste entendimento que a (IFLA) sinalizou que as bibliotecas podem contribuir com a implementação da Agenda 2030 da ONU.

Deste modo, o objetivo focal do estudo visa: propor ações de alinhamentos com o Internacional Advocacy Program (IAP) da IFLA, localmente, nasensibilização das bibliotecas das universidades públicas sediadas no município de Florianópolis-SC, incentivando a promoção de seu engajamento na promoção de ações e serviços que se alinhem à Agenda 2030 da ONU.

Quanto aos caminhos metodológicos, trata-se de uma pesquisa descritiva com abordagem qualitativa e quantitativa, por proporcionar o conteúdo, advindos destas ações pois serão apresentados na forma de texto e com auxilio de gráficos estatísticos, visando institucionalizar a cultura de sustentabilidade nas bibliotecas e que serão apresentados na forma de texto e com auxilio de gráficos estatísticos, visando institucionalizar a cultura de sustentabilidade nas bibliotecas.

\section{ASPECTOS CONCEITUAIS}

O conceito sustentável sempre esteve ligado às questões financeiras, mas mais recentemente este conceito foi ampliado para o desenvolvimento de uma consciência sustentável, em que cada pessoa tem o dever de dar sua contribuição. Para iniciar, a mudança de visão sobre sustentabilidade tem que se identificar ações práticas que podem ser vivenciadas cotidianamente nas organizações e, de maneira mais abrangente com a sustentabilidade do planeta.

O surgimento de uma consciência ambiental aos poucos toma forma e vem ganhando espaço em diferentes contextos sociais mundiais, mas é na educação que está à chave do desenvolvimento sustentável. Uma educação ofertada a todos os membros da sociedade, segundo modalidades novas e com a ajuda de tecnologias novas, de tal 


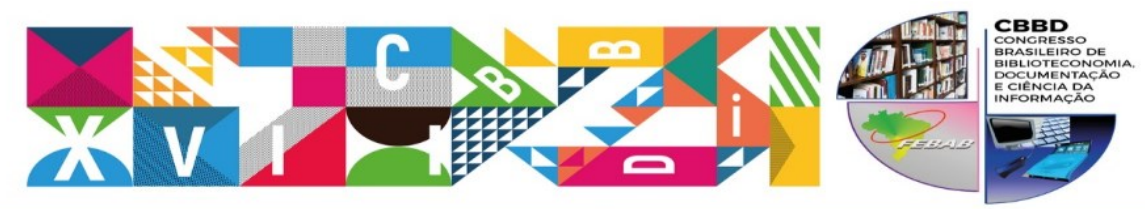

XXVII CONGRESSO BRASILEIRO DE BIBLIOTECONOMIA,

DOCUMENTAÇÃO E CIÊNCIA DA INFORMAÇĀO

TEMA CENRPA: Objetivos para o Desenvolvimento Sustentável das Naçōes Unidas:
como as bibliotecas podem contribuir com a implementaça da Agenda 2030

maneira que cada um se beneficie de chances reais de se instruir ao longo da vida (MAYOR,1998).

Numa reunião de chefes de Estado, de governo e de altos representantes reunidos na sede das Nações Unidas, em Nova York, de 25 a 27 de setembro de 2015, foi discutida a Agenda 2030, cujo objetivo busca firmar compromisso para o desenvolvimento sustentável global. Dessa forma, foi criada a Agenda, estruturada em 17 objetivos com um total de 179 metas que abrangem o desenvolvimento econômico, ambiental e social, sendo elaborada de forma coletiva para que todos os países que são membros da ONU se empenham ativamente em tornar o mundo melhor para o seu povo e para o planeta.

A InternationalFederation of Library AssociationsandInstitutions (IFLA)participou ativamente na criação da Agenda 2030 e de acordo com a referida federação, as bibliotecas são instituições-chave para alcançar os Objetivos, defendendo a inclusão do acesso à informação, a salvaguarda do patrimônio cultural e o acesso às Tecnologias da Informação e da Comunicação.

Para dar prosseguimento ao estudo utilizou-se encaminhamentos que entendem como advocacy a luz do que postula Patri(2011, p. 143):

é o ato de advogar, exercido pelas organizações sem fins lucrativos, quando estas defendem seus próprios interesses, tentam influenciar algum aspecto da sociedade ou quando estes apelam para indivíduos para que mudem seus comportamentos. (PATRI, 2011, p. 143).

De acordo com CanadianAssociation of Public Libraries (CAPL), o advocacy é um movimento planejado, deliberado e sustentado, com objetivo central de aumentar a conscientização de um problema ou problemas. 0 advocacyé um processo contínuo de ações, buscando a compreensão dos indivíduos envolvidos, criando de forma incremental durante um longo período de tempo. (CANADIAN ASSOCIATION..., 2011, tradução nossa).

Segundo Silva et al. (2015), o movimento advocacy "tem crescido e se valorizado cada vez mais dentro da Biblioteconomia", com objetivo focal de "dar visibilidade aos serviços promovidos pelas bibliotecas, mas também em sua defesa e na valorização do trabalho do bibliotecário". (SILVA et al., 2015, p. 473). 

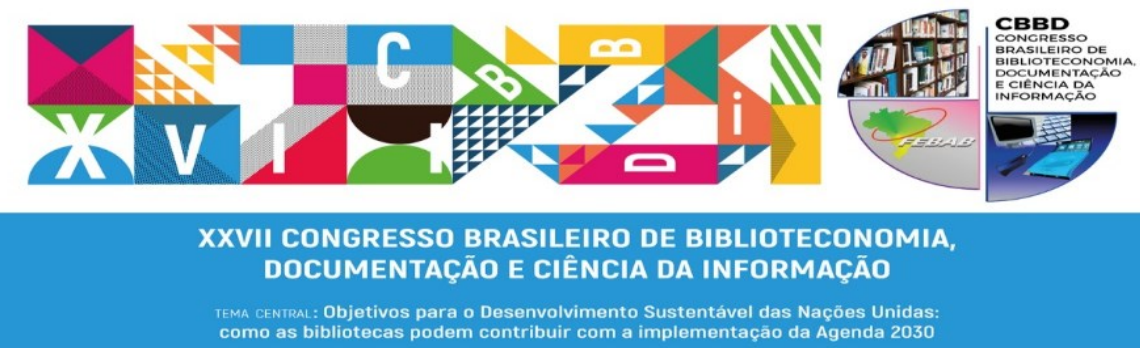

Para realizar um programa efetivo de advocacy, os defensores da biblioteca devem ter um plano, no qual o movimento advocacy se desenvolve durante um longo período de tempo. "não pode desperdiçar o tempo das pessoas e recursos". (CANADIAN ASSOCIATION..., 2011, tradução nossa).

A CAPL (2011), expõe que o planejamento do movimento advocacy pode ser resumido nas seguintes etapas: a) definir os objetivos específicos do tempo e mensuráveis; b) determinar o público-alvo e o que já se conhece sobre eles e; c) desenvolver estratégias. (CANADIAN ASSOCIATION..., 2011, tradução nossa).

OGovernment Relations Committee (OCL), ao disponibilizar aos gestores de bibliotecas públicas o "Library Advocacy: A Handbook for Ohio Public Libraries", explica que o movimento advocacy nas bibliotecas deve estar "vinculado aos objetivos gerais da biblioteca e ao programa de conscientização pública em curso". E para montar uma efetiva campanha de advocacy, deve-se ter um plano de ação com um objetivo focal e objetivos de apoio, tendo uma visão evidenciado em um plano de ação de defesa das bibliotecas, do profissional bibliotecário e dos objetivos de uma vida prospera para a comunidade. (OLC GOVERNMENT..., 2002). Ou seja, antes mesmo de colocar o plano em prática, é importante saber exatamente o que se deseja, quais os reais objetivos e quais resultados que se busca alcançar.

Alinhando o plano de ação e objetivos estratégicos, a IFLA patrocinou com colaboração de várias associações de bibliotecários de diferentes países, o Programa Internacional de Advocacy,que segundo FERRARI (2017, p. 2, tradução nossa), foi “um marco que mostrou que as bibliotecas realmente têm um papel preponderante na sociedade". Com isso, oportunizou e incentivou à essas associações, trabalharem com os profissionais e alinharem as ações que devem ser feitas para e com os governos. (FERRARI, 2017, tradução nossa).

Lankes (2016), comenta que atualmente precisamos de bibliotecas e bibliotecários preparados para desenvolver ações estratégicas que vão além do trabalho tecnicista, mas que proporcionem aos seus usuários, um local de aprendizagem, de resolução de problemas e que incentivem que todos advoguem por sua comunidade, 


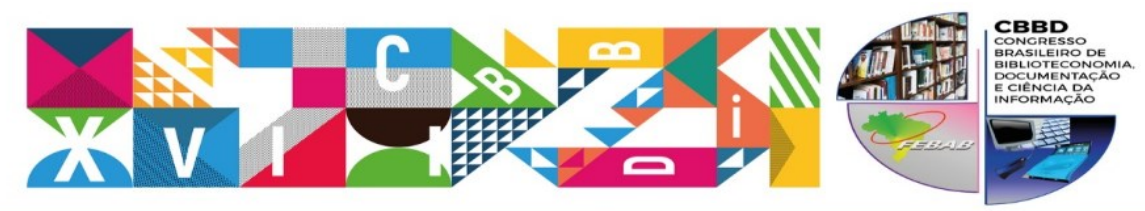

XXVII CONGRESSO BRASILEIRO DE BIBLIOTECONOMIA,

DOCUMENTAÇÃO E CIÊNCIA DA INFORMAÇÃO

TEMA CENIral: Objetivos para o Desenvolvimento Sustentável das Naçōes Unidas:
como as bibliotecas podem contribuir com a implementaçăo da Agenda 2030

pois todas as bibliotecas "fazem parte da educação dos cidadãos para uma participação democrática" (LANKES, 2016, p. 47).

Ferrari (2017, tradução nossa), descreve que no Brasil, após terem recebido o treinamento, pela IFLA, com objetivo de implantarem, mobilizarem e disseminarem o movimento advocacy no país, alinharam duas frentes para o programa: mobilizar as associações e profissionais-chave e influentes para formar um comitê nacional e; divulgar a agenda entre os profissionais bibliotecários.

Especialmente no segundo aspecto do plano de advocacy, Ferrari (2017, tradução nossa), comenta que o objetivo de divulgar a agenda entre os profissionais, além disso, deve-se fornecer informações às equipes da biblioteca. Ferrari (2017, tradução nossa), discorre ainda, que:

a FEBAB deve mostrar às bibliotecas que a Agenda 2030 pode ser vista como uma estratégia de sustentabilidade e melhoria da percepção da sociedade para o trabalho que as bibliotecas realizam diariamente, o que frequentemente não é percebido. Isso ocorre porque, no Brasil, as bibliotecas sofrem com o estereótipo de que são apenas lugares para livros, lugares para estudiosos, lugares para poucas pessoas. (FERRARI, 2017, p. 3, tradução nossa)

Sendo assim, as associações e profissionais brasileiros devem alinhar ações estratégicas para disseminar e conscientizar os gestores de bibliotecas sobre a importância do movimento de advocacy, e consequentemente, a Agenda 2030 e Os Objetivos do Desenvolvimento Sustentável (ODS).

\section{PERCURSOS METODOLÓGICOS DA PESQUISA}

Este estudo surgiu a partir de dois eventos distintos. Primeiramente o caminho metodológico utilizado caracterizou-se como exploratório, abordagem qualitativa e como participantes 63 gestores de Bibliotecas Universitárias Federais. Buscou-se pesquisar a compreensão dos Gestores das Bibliotecas das universidades públicas federais sobre a Agenda 2030. Como não se obteve respostas, mesmo com insistência no 


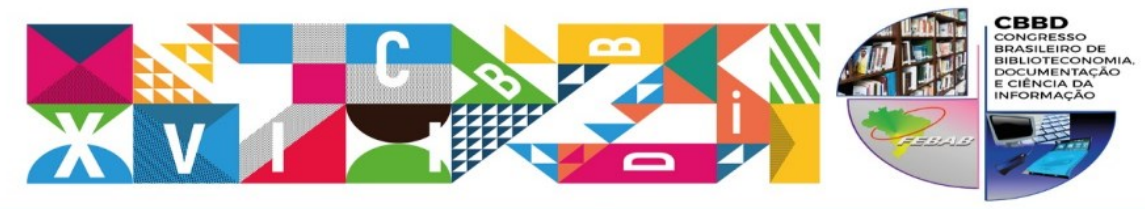

XXVII CONGRESSO BRASILEIRO DE BIBLIOTECONOMIA, DOCUMENTAÇÃO E CIÊNCIA DA INFORMAÇÃO

TEMA CENrRaA: Objetivos para o Desenvolvimento Sustentável das Naçōes Unidas:
como as bibliotecas podem contribuir com a implementaçâo da Agenda 2030

reenvio da pesquisa, os pesquisadores visualizaram a possibilidade de elaborar ações para disseminar localmente no cotidiano bibliotecário, a questão.

No segundo momento, procedeu-se uma pesquisa bibliográfica, que acreditou-se ser relevante verificar o estado da arte sobre o tema em questão e, para tanto, procedeuse a um levantamento em nível nacional com as palavras chaves sustentabilidade e bibliotecae, 08 artigos foram recuperados, sendo que apenas dois artigos estavam em consonância com propósito deste relato, os mesmos são respectivamente dos autores Silveira, C. Z., Juliani, J.P., Chagas, Ricardo, intitulado 0 papel das Bibliotecas Universitárias no desenvolvimento sustentável: uma análise dos serviços da Biblioteca Central da UFSC em da autora Weber, C. As Bibliotecas e o aporte para o desenvolvimento sustentável.

O próximo percurso metodológicofoiutilizaro advocacy, entendendo-o como um instrumento que busca sensibilizar e conscientizar sobre as importantes causas a serem defendidas na inserção das bibliotecas nosODS das Nações Unidas.

Para tanto, elencou-se ações de alinhamento com o advocacy proposto pela Federação Internacional de Associações e Instituições Bibliotecárias (IFLA) que é o principal organismo internacional que representa os interesses da biblioteca e dos serviços de informação e seus usuários, constante do Programa de Ação da IFLA para o Desenvolvimento através das Bibliotecas, de outubro 2015. (IFLA, 2015).

Estas ações de advocacyserão trabalhadas localmente, na organização de atividades que aumentem a consciênciada Agenda 2030 e, como local definiu-se asbibliotecas universitárias e o cursos de Biblioteconomia das Universidades pública de Florianópoli-SC, e os atores alvo desse processo os bibliotecários destas bibliotecas, discentes e docentes dos cursosde graduação em Biblioteconomia.

Como instrumento de coletadados elaborou-se um Plano de Ação que permite apresentar oandamento das atividades, as estratégias, a execução, e, por fim revelará todoo histórico das ações executadas ou previstas.

Trata-se de uma pesquisa descritiva com abordagem qualitativa e quantitativa, por proporcionaro conteúdo, advindo destas ações e que serão apresentados na forma 


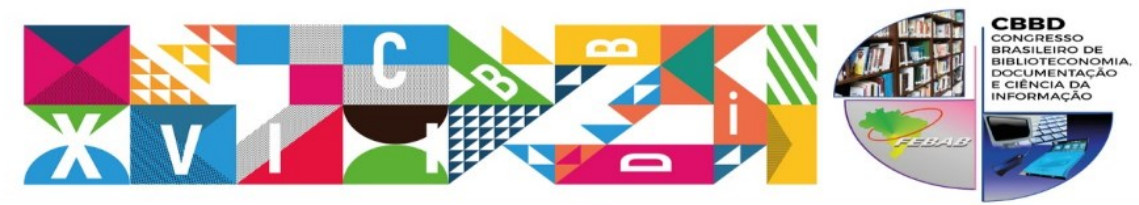

XXVII CONGRESSO BRASILEIRO DE BIBLIOTECONOMIA,

DOCUMENTAÇÃO E CIÊNCIA DA INFORMAÇÃO

TEMA CENIral: Objetivos para o Desenvolvimento Sustentável das Naçōes Unidas:
como as bibliotecas podem contribuir com a implementaçâo da Agenda 2030

de texto e com auxilio de gráficos estatísticos, visando institucionalizara cultura de sustentabilidade nas bibliotecas.

\section{PROPOSTA DE ADVOCACY: NO CONTEXTO BIBLIOTECONÔMICO DE FLORIANÓPOLIS/SC}

Buscou-se, deste modo, dar subsídios, promoção e apoio às bibliotecas no desempenho, no planejamento e implementação de ações que contribuam com a Agenda 2030 da ONU.

Estas ações iniciaramcom a elaboração de um Projeto que foi apresentado e está sendo desenvolvido no Programa de Pós Graduação em Ciência da Informação da Universidade Federal de Santa Catarina (PGCIn/UFSC) intitulado Gestão de Unidades de Informação e Competências profissionais: uma aproximação necessária com a sustentabilidade, que resumidamente busca a sustentabilidade em unidades de informação, interfaces impostas pelos desafios de gestão destas Unidades no estabelecimento de estratégias para o desenvolvimento de competências profissionais, sedimentada por uma cultura de pró-atividade, potencializando o desenvolvimento de serviços e produtos que atualmente carecem de discussão e de total inserção do profissional nestes cenários.

Em maio de 2017, submeteu- se um artigo a um Periódico da área daCiência da Informação,cujo objetivo foi analisar as ações desenvolvidas pelas Bibliotecas Públicas Catarinenses em consonância com Agenda 2030 para o Desenvolvimento Sustentável da ONU e,como resultado deste estudo,verificou-se que ações para o desenvolvimento sustentável não estão contempladas nas bibliotecas estudadas e, que para que isto ocorra tudocomeça por um ambiente propício à aprendizagem, ao trabalho colaborativo, estabelecimento de parcerias entre governo, comunidade e instituições locais para cumprir minimamente os objetivos da Agenda 2030.

Como ação de Alinhamento do Desenvolvimento Sustentável em consonância com a Agenda 2030, a IFLA entende que agir localmente e organizar atividades sobre a Agenda 2030 em suas próprias instituições são atribuições dos bibliotecários. Com esta 


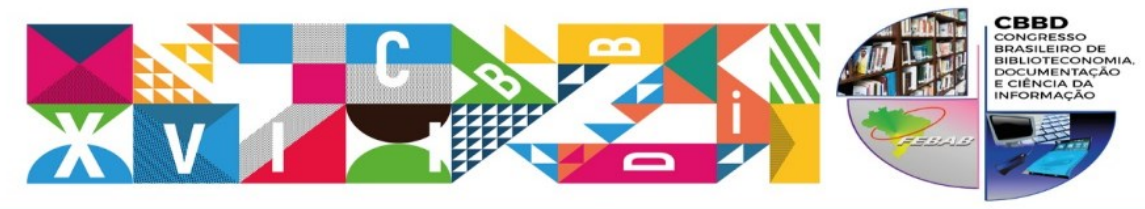

XXVII CONGRESSO BRASILEIRO DE BIBLIOTECONOMIA, DOCUMENTAÇÃO E CIÊNCIA DA INFORMAÇĀO

TEMA CENrRaA: Objetivos para o Desenvolvimento Sustentável das Naçōes Unidas:
como as bibliotecas podem contribuir com a implementaçâo da Agenda 2030

finalidade será utilizadoo kit de ferramentas destinado aos bibliotecários envolvidos em atividades nacionais de advocacy, que se propõem a ajudar a:

a) Compreender o processo da Agenda 2030 da ONU e o trabalho de Advocacy da IFLA;

b) Compreender como a Agenda2030 da ONU será implementada em nível nacional;

c) Organizar encontros com decisores políticos para demonstrar a contribuição que as bibliotecas e o acesso à informação proporcionam para o desenvolvimento nacional e em todos os ODS;

d) Monitorizar a Agenda 2030 da ONU e a implementação dos ODS;

e)Informar os utilizadores da biblioteca sobre os ODS (IFLA,2017).

A partir do entendimento de que Advocacy é a atividade de influenciar a sociedade e, que as bibliotecas devem ser parceiras e, que podem contribuir para o desenvolvimento de todas as pessoase organizações no acesso à informação, como parte dos planos de desenvolvimento nacionais e regionais e que estes compactuam para o cumprimento da a Agenda 2030 para o Desenvolvimento Sustentável (AGENDA 2030 DA ONU).

Neste cenário é relevante que se compreenda o processo da agenda 2030 e o trabalho de defesa da IFLA sobre a importância deste espaço como contribuição relevante para os ODS e, conscientização como forma de alavancar ações concretas dos 17 objetivos da Agenda 2030 da ONU.

Entre os objetivos da ODS,pontua-se a"A Disseminação da informação e das tecnologias da comunicação e interconectividade global tem um grande potencial para acelerar o progresso humano, para eliminar o fosso digital e para o desenvolvimento de sociedades do conhecimento, assim como a inovação científica e tecnológica [...]" que papel das bibliotecas o tratamento deste assunto.

As ações de advocacyaqui se propõem trabalhar localmente com os segmentos profissionais e acadêmicos da Biblioteconomia emFlorianópolis, Santa Catarina.

Em Florianópolis, estão localizadas duas Universidades públicas que oferecem o curso de Biblioteconomia e, são responsáveis pela formação desse profissional, para todo o estado de Santa Catarina. Em 1973, foram criados os dois cursos de 


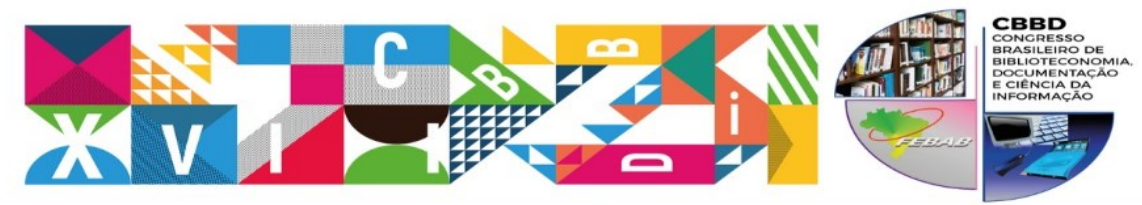

XXVII CONGRESSO BRASILEIRO DE BIBLIOTECONOMIA,

DOCUMENTAÇÃO E CIÊNCIA DA INFORMAÇÃO

TEMA CENIRal: Objetivos para o Desenvolvimento Sustentável das Naçōes Unidas:
como as bibliotecas podem contribuir com a implementaçăo da Agenda 2030

Biblioteconomia,da Universidade do Estado e o Curso de Biblioteconomia da Universidade Federal de Santa Catarina (OHIRA, et. al 1999).

Neste contexto biblioteconômico em que serão realizadas as ações de advocacy, nas bibliotecas e com acadêmicos das duas instituições, inicialmente por meio de palestra, se pretende:

a) inserir por meio de sensibilização e conscientização os bibliotecários no processo da Agenda 2030 da ONU e o trabalho de Advocacy da IFLA;.

b) Promover ações para que os bibliotecários sejammultiplicadores destas ações para seu contexto interno e externo a instituição;

c) Conhecer ações que a biblioteca realiza voltadosao desenvolvimento sustentável a partir da percepção da comunidade envolvida.

d) Elaboração de produtos, serviços e ações voltados para advocacy proposto pela IFLA para as ODS nas bibliotecas.

Concomitante a todas estas ações pretende-se buscar o apoio da mídia e dos formadores de opinião e, também planejar cuidadosamente uma estratégia de comunicação. Pretende-se, também, identificar quem são os tomadores de decisão chave ou as pessoas de influência e trabalhar estrategicamente para conseguir reuniões com essas pessoas.Convidar acadêmicos respeitados e outras autoridades para fazerem parte dessas reuniões e darem suporte à causa e à sua argumentação.

Desta maneira, evidencia-se que este relato de pesquisa esta em fase de aplicação e, que dentro de pequeno espaço de tempo poderá se conhecer a realidade e divulgá-la como importante instrumento que venha modificar significantemente o papel e a importância da bibliotecas e das informações para todos os cidadãos, para os órgão políticos e educacionais e que isto se reverta em benefício da melhoria da qualidade de vida das pessoas no combate ao analfabetismo, à fomee melhoria das condições do planeta, entendendo que ações pequenas podem melhorar significativamente a qualidade de vida de todos.

\section{CONSIDERAÇÕES FINAIS}




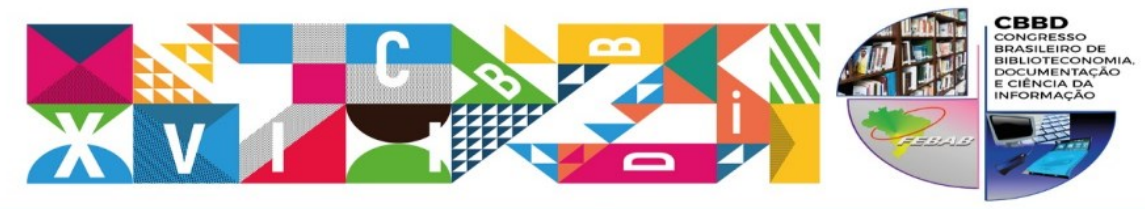

XXVII CONGRESSO BRASILEIRO DE BIBLIOTECONOMIA, DOCUMENTAÇÃO E CIÊNCIA DA INFORMAÇÃO

TEMA CEnrral: Objetivos para o Desenvolvimento Sustentável das Naçōes Unidas:
como as bibliotecas podem contribuir com a implementaçăo da Agenda 2030

As bibliotecas universitárias precisam estar inseridas nas discussões acerca do desenvolvimento sustentável e, para isso, têm que ser percebidas como organismos ativos, dinâmicos e em mutação, necessitando estar engajadas nas diretrizes que norteiam as práticas sustentáveis e, conhecer o estado da arte mediante os levantamentos bibliográficos realizados contribuiu para ampliar os conhecimentos sobre a temática.

Pretendia-se, inicialmente, com as respostas ao questionário enviado, conhecer as estratégias desenvolvidas pelas bibliotecas universitárias, que efetivamente contribuíssem com os objetivos e metas propostos pela Agenda 2030. Para os autores, porém, o não retorno por parte dos dirigentes das bibliotecas das universidades ao questionário evidenciou a necessidade de se promover ações de sensibilização e conscientização.

A partir do entendimento de que o assunto ainda não faz parte do contexto biblioteconômico e, para cumprir os objetivos propostos, para este estudo criou-se uma equipe composta por cinco bibliotecários inseridos na docência, na pesquisa, na profissão e acadêmico do curso de Biblioteconomia com o propósito de realizar uma proposta de sensibilização junto às bibliotecas das universidades públicas do município de Florianópolis-SC, valendo-se do ferramental proposto pela IFLA.

OPrograma Internacional de Advocacy da IFLA (IAP) busca subsidiar as bibliotecas com a finalidade de promover e apoiar para desempenhar e implementar a Agenda 2030, as ações propostas buscam defender interesse e influenciar a mudança de comportamento do individuo dando visibilidade da importância da educação e da biblioteca para o desenvolvimento sustentável em todos os cenários.

São as bibliotecas universitárias, o centro de ação para o usuário nainstituição mantenedora na qual estão inseridas, e estas dependem dapromoção ao acesso à informação e da interação dos pressupostos e práticas individuais na aquisição e no compartilhamento de conhecimentos para melhoria da qualidade de vida da sociedade e do planeta.

\section{REFERÊNCIAS}




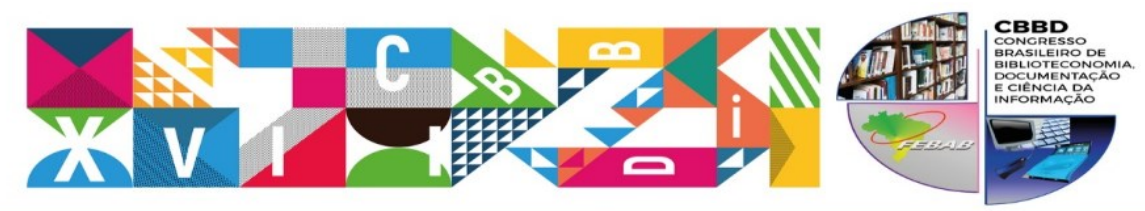

XXVII CONGRESSO BRASILEIRO DE BIBLIOTECONOMIA, DOCUMENTAÇÃO E CIÊNCIA DA INFORMAÇÃO

TEMA CENIral: Objetivos para o Desenvolvimento Sustentável das Naçōes Unidas:

CBBD. Apresentação do 27º Congresso Brasileiro de Biblioteconomia e Documentação 2017.

Disponível em: http://www.cbbd2017.com/apresentacao.Acesso em 06 jul. 2017

COMMITTEE, Olc Government Relations. Library Advocacy: A Handbook for Ohio Public Libraries. 2002. Disponível em: <http://www.olc.org/pdf/in_advocacy_bklt.pdf>. Acesso em: 15 nov. 2017.

FEBAB. Federação Brasileira de Associações de Bibliotecários, Cientistas da Informação e Instituições. 2017. Disponível em: <http://www.febab.org.br/>. Acesso em: 9 nov. 2017

FEDERAÇÃO INTERNACIONAL DE ASSOCIAÇÕES E INSTITUIÇÕES BIBLIOTECÁRIAS (IFLA)..Las bibliotecas y la implementación de la Agenda 2030 de la ONU. Disponível em:

https://www.ifla.org/files/assets/hq/topics/libraries-development/documents/libraries-un2030-agenda-toolkit-es.pdf. Acessoem: 27 jun. 2017.

. Toolkit: Libraries and National Development Plans.(October 2015). Disponível em: https://www.ifla.org/publications/node/10156. Acesso em 26/06/2017.

Las bibliotecas, las actividades de defensa y promoción y la implementación de la agenda 2030. 24 march 2016. Disponível em: https://www.ifla.org/node/10345. ACESSO EM; 19 de jun.2017

FERRARI, Adriana Cybele. Brazilian Libraries and the 2030 Agenda: actions to support compliance with ODS. In: IFLA WLIC 2017, 83., 2017, Wrocław. Paper presented. Haia: IFLA Library, 2017. p. 1 - 8. Disponível em: <http://library.ifla.org/1626/>. Acesso em: 9 nov. 2017. LANKES, David. Expect more: melhores bibliotecas para um mundo complexo. São Paulo: Febab, 2016. 172 p. Tradução de Jorge Prado.

LIBRARIES, CanadianAssociation Of Public. Library Advocacy Now! A Training Program For Public Library Staff and Trustees. 2011. Disponível em: <http://cla.ca/wpcontent/uploads/LibraryAdvocacyNow.pdf>. Acesso em: 11 nov. 2017.

MAYOR, F. Preparar um futuro viável: ensino superior e desenvolvimento sustentável. In: CONFERÊNCIA MUNDIAL SOBRE O ENSINO SUPERIOR. Tendências de educação superior para o século XXI, 3. Anais ... Paris: UNESCO/CRUB, 1998.

PATRI, E.C. Relações governamentais, Lobby e advocacy no contexto de publicaffairs.

orGAnICoM. n. 14, 2011. Disponível em:

http://www.revistaorganicom.org.br/sistema/index.php/organicom/article/viewFile/397/385 . Acessoem: 06 jul.2017.

SILVA, Andreia Sousa da et al. Associação Catarinense de bibliotecários: 40 anos de serviços prestados na defesa e valorização da biblioteconomia Catarinense. In: CONGRESSO BRASILEIRO DE BIBLIOTECONOMIA E DOCUMENTAÇÃO, 26., 2015, São Paulo. Anais... . São Paulo: Febab, 2013. p. 472 - 485. Disponível em: <https://rbbd.febab.org.br/rbbd/article/viewFile/523/444>. Acesso em: 11 nov. 2017. 


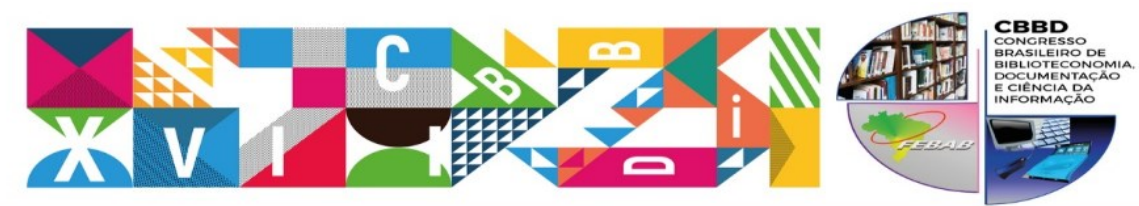

\section{CONGRESSO BRASILEIRO DE BIBLIOTECONOMIA, DOCUMENTAÇÃO E CIÊNCIA DA INFORMAÇÃO \\ TEMA CENIral: Objetivos para o Desenvolvimento Sustentável das Naçōes Unidas:
como as bibliotecas podem contribuir com a implementaçăo da Agenda 2030}

SILVEIRA, C. Z., JULIANI, J.P., CHAGAS, Ricardo, intitulado 0 papel das Bibliotecas Universitárias no desenvolvimento sustentável: uma análise dos serviços da Biblioteca Central da UFSC In: XIX Seminário Nacional de Bibliotecas Universitárias. Disponivel

em<www.periodicos.ufam.edu.br/anaissnbu/article/download/3250/2893>. Acesso em: 07 de jul.2017.

WEBER, C. As bibliotecas e o aporte para o desenvolvimento sustentável. Atos do Congresso Responsabilidade e Reciprocidade. Fundação Antônio Meneghetti\& Faculdade Antônio Meneghetti - Recanto Maestro 2011. Disponível em:www.reciprocidade.org.br. Acesso em: 30 maio 2016. 